\title{
Comparison of Proportional Assist Ventilation Plus, T-Tube Ventilation, and Pressure Support Ventilation as Spontaneous Breathing Trials for Extubation: A Randomized Study
}

\author{
Sandy Nogueira Teixeira PT, Erica Fernanda Osaku PT PhD, \\ Claudia Rejane Lima de Macedo Costa PT PhD, Beatriz Fernandes Toccolini PT, \\ Nicolle Lamberti Costa PT, Maria Fernanda Cândia PT, Marcela Aparecida Leite PT, \\ Amaury Cezar Jorge MD MSc, and Péricles Almeida Delfino Duarte MD PhD
}

\begin{abstract}
BACKGROUND: Failure to wean can prolong ICU stay, increase complications associated with mechanical ventilation, and increase morbidity and mortality. The spontaneous breathing trial (SBT) is one method used to assess weaning. The aim of this study was to assess proportional assist ventilation plus $(\mathrm{PAV}+)$ as an SBT by comparing its applicability, safety, and efficacy with T-tube and pressure support ventilation (PSV). METHODS: A randomized study was performed involving 160 adult subjects who remained on mechanical ventilation for $>24 \mathrm{~h}$. Subjects were randomly assigned to the PAV+, PSV, or T-tube group. When subjects were ready to perform the SBT, subjects in the PAV + group were ventilated in PAV+ mode (receiving support of up to $40 \%$ ), the pressure support was reduced to $7 \mathrm{~cm} \mathrm{H}_{2} \mathrm{O}$ in the PSV group, and subjects in the T-tube group were connected to one T-piece with supplemental oxygen. Subjects were observed for signs of intolerance, whereupon the trial was interrupted. When the trial succeeded, the subjects were extubated and assessed until discharge. RESULTS: The subjects were predominantly male $(66.5 \%)$, and the leading cause of admission was traumatic brain injury. The groups were similar with respect to baseline characteristics, and no significant difference was observed among the groups regarding extubation success or failure. Analysis of the specificity and sensitivity revealed good sensitivity for all groups; however, the PAV + group had higher specificity (66.6\%) and higher sensitivity $(97.6 \%)$, with prediction of $\sim 92.1 \%$ of the success and failure events. CONCLUSIONS: No significant differences in the groups was observed regarding the rate of extubation failure, duration of mechanical ventilation, and ICU and hospital stay, indicating that PAV+ is an alternative for use as an SBT. Key words: intensive care units; ventilator weaning; airway extubation; respiration; artificial; respiratory insufficiency; protocols; mortality. [Respir Care 2015;60(11):1527-1535. (C) 2015 Daedalus Enterprises]
\end{abstract}

Introduction

Weaning refers to the gradual and progressive transition from mechanical ventilation to spontaneous breathing in

\footnotetext{
The authors are affiliated with the Intensive Care Unit, and Dr Jorge and Duarte are also affiliated with the Department of Medicine, Western Paraná State University Hospital, Cascavel, Paraná, Brazil.
}

The authors have disclosed no conflicts of interest.

Correspondence: Sandy Nogueira Teixeira PT, Western Paraná State University Hospital, Avenida Tancredo Neves 3224, Santo Onofre, 85806470 Cascavel, Paraná, Brazil. E-mail: sandy.fisio@hotmail.com. patients on invasive mechanical ventilation for $>24 \mathrm{~h} .^{1}$ Early discontinuation of mechanical ventilation reduces the risk of developing ventilator-associated pneumonia and upper-airway injuries. ${ }^{2}$ However, when not well assessed, failure to wean can prolong both mechanical ventilation and ICU/hospital stay and can increase the rate of reintubation and complications associated with invasive mechanical ventilation, thereby increasing morbidity and mor-

DOI: $10.4187 /$ respcare. 03915 
tality. Thus, updating the weaning protocol to prevent such failures is important. ${ }^{2-7}$

Even when weaning criteria are met and a successful spontaneous breathing trial (SBT) is conducted, a planned extubation may fail in $\sim 10-20 \%$ of cases. ${ }^{8}$ Several authors have pointed out that the SBT protocols and screening conducted by physiotherapists yield good results and have proven effectiveness and are therefore highly recommended.9-12

\section{See the Related Editorial on Page 1705}

Discontinuation of mechanical ventilation involves several steps, one of which is an SBT. If patients tolerate an SBT, they are eligible for extubation. ${ }^{13}$ An SBT is simple and among the most effective for weaning. The most commonly used techniques are the $\mathrm{T}$-tube and pressure support ventilation (PSV) of up to $7 \mathrm{~cm} \mathrm{H}_{2} \mathrm{O}$. $^{7}$

New modes are being studied, such as proportional assist ventilation plus $(\mathrm{PAV}+)$, which is a spontaneous mode of mechanical ventilation designed primarily to respond to changes in a patient's ventilator demand. It provides patients with synchronized support, where assistance is instantaneous in response to the patients' respiratory efforts. ${ }^{14}$ Hence, the pressure applied to the airways during inspiration is proportional to the pressure provided to the inspiration muscles, ${ }^{15}$ with the pressure applied by the ventilator increasing if patient effort increases. ${ }^{14}$ Current data on PAV+ indicate that it can sustain the same patients who received PSV, that is, those who can breathe spontaneously and manage their ventilation. ${ }^{16}$ Nevertheless, studies are lacking in which PAV+ weaning is used, especially as an SBT.

The aim of this study was to analyze PAV + mode as an SBT. We assessed the applicability, safety, and efficacy of $\mathrm{PAV}+$ compared with the current methods (T-tube and PSV), with extubation success and failure as the main outcomes and mortality, mechanical ventilation duration, and ICU and hospital stay as the secondary outcomes.

\section{Methods}

\section{Selection and Randomization of Subjects}

This prospective non-blinded randomized controlled trial was conducted from November 2012 to November 2013 in the adult ICU of the University of Paraná West Hospital in Cascavel, Brazil. This study was approved by the research ethics committee of the State University of West Paraná (opinion 436 770). Informed consent was obtained from subjects or their legal guardians.

The study included subjects hospitalized in the ICU who remained on mechanical ventilation for $>24 \mathrm{~h}$ (Fig. 1). The exclusion criteria were: tracheostomy, death without weaning, self-extubation, extubation by clinical decision (decided

\section{QUICK LOOK}

\section{Current knowledge}

Discontinuation of mechanical ventilation should be accomplished when the patient's ability to breathe unassisted is identified. Both premature and delayed ventilator discontinuation are associated with significant morbidity. Daily spontaneous breathing trials (SBTs) are the current evidence-based standard of care in determining the time of ventilator discontinuation.

\section{What this paper contributes to our knowledge}

This study compared SBTs using a T-tube, pressure support ventilation, and proportional assist ventilation in mixed surgical and medical subjects. No significant differences were found in the rate of extubation failure, duration of mechanical ventilation, or ICU and hospital stays between groups.

and performed by staff, not meeting protocol requirements), presence of progressive neuromuscular disease, and spontaneous ventilation maintenance (not mechanical ventilation). The primary extubation of the subject was considered for the analysis.

The sample calculation was defined by convenience. After sample collection, assuming a medium effect size of 0.25 and type- 1 error of 0.05 with 3 groups (T-tube, PSV, and PAV+), a power analysis was performed $\left(\mathrm{G}^{*}\right.$ Power 3.1 .3 , HeinrichHeine-University Düsseldorf, Düsseldorf, Germany), with a value of 0.81 for the 160 adult subjects that were randomized.

\section{Randomization}

The subjects were randomized after discontinuation of sedation using a simple draw for 3 distinct groups: PAV+, PSV, and T-tube. To start the protocol, SBT subjects were required to satisfy the following criteria: improvement or resolution of the cause that led to acute respiratory failure, adequate gas exchange, $\mathrm{P}_{\mathrm{aO}_{2}} \geq 60 \mathrm{~mm} \mathrm{Hg}$ with $\mathrm{F}_{\mathrm{IO}_{2}} \leq 0.45$, $\mathrm{P}_{\mathrm{aO}_{2}} / \mathrm{F}_{\mathrm{IO}_{2}}>200 \mathrm{~mm} \mathrm{Hg}$, PEEP $\leq 8 \mathrm{~cm} \mathrm{H} \mathrm{H}_{2} \mathrm{O}$, Glasgow coma scale score $\geq 9$, peripheral temperature $<38^{\circ} \mathrm{C}$, low doses of vasoactive drugs, and hemodynamic stability (between 70 and $105 \mathrm{~mm} \mathrm{Hg}$ ).

Subjects who qualified for the protocol underwent predictive testing for extubation: assessment of maximum inspiratory pressure and rapid shallow breathing index (RSBI). The maximum inspiratory pressure measurement was performed as described by Caruso et al ${ }^{17}$ with an analog manometer (0 to $-300 \mathrm{~cm} \mathrm{H}_{2} \mathrm{O}$; Class $\mathrm{B}$, GeRar, São Paulo, Brazil) adapted to a one-way valve. A Wright Mark 8 respirometer (Ferraris Medical, Louisville, Colo- 


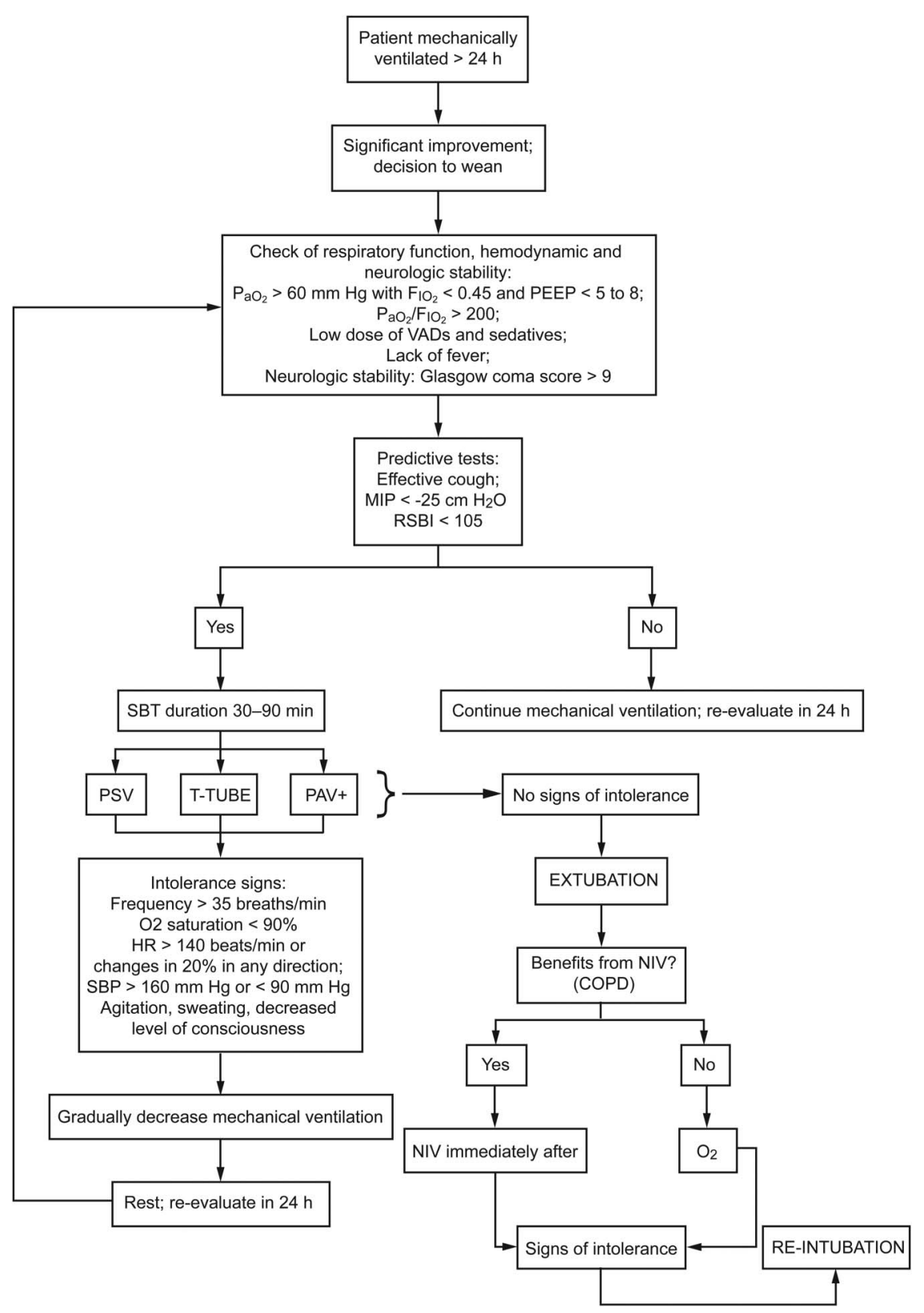

Fig. 1. Study protocol. Subjects with hemodynamic, respiratory, and neurologic stability and positive predictive index were randomized to 3 groups (T-tube, pressure support ventilation [PSV], and proportional assist ventilation plus [PAV +]) to perform a spontaneous breathing trial (SBT). The subjects who showed no signs of intolerance were extubated. Those who failed the SBT were assessed the following day. $\mathrm{VADs}=$ vasoactive drugs; MIP = maximum inspiratory pressure; $\mathrm{RSBI}=$ rapid shallow breathing index; $\mathrm{HR}=$ heart rate; NIV = noninvasive ventilation.

rado) was used for the RSBI, as described by Yang and Tobin. ${ }^{18}$

Subjects who underwent an SBT had a maximum inspiratory pressure of $-25 \mathrm{~cm} \mathrm{H}_{2} \mathrm{O}$ or less, an RSBI of $\leq 105$, an effective cough of $>3(0=$ no cough; $1=$ audible air movement through the endotracheal tube, but no cough; 2 = weak cough; 3 = cough clearly audible; $4=$ heavy cough; $5=$ multiple-cough sequence), ${ }^{19}$ and positive cuff-leak tests. If subjects were not able to start the protocol, they were maintained on mechanical ventilation and reassessed after $24 \mathrm{~h}$.

Personal and clinical data were collected: age, sex, ICU days, hospitalization days, invasive mechanical ventilation days, mechanical ventilation weaning hours, APACHE (Acute Physiology and Chronic Health Evaluation) II score at admission, Sequential Organ Failure Assessment (SOFA) score at admission, Glasgow coma scale score, maximum inspiratory pressure, $\mathrm{RSBI}, \mathrm{P}_{\mathrm{aO}} / \mathrm{F}_{\mathrm{IO}_{2}}$, breathing frequency, 
and ventilator data (recorded daily). Furthermore, on the extubation day, the presence of delirium was analyzed using the Confusion Assessment Method for the Intensive Care Unit (CAM-ICU), and the muscle strength of the extremities was assessed using the Medical Research Council (MRC) scale $(0-5: 0=$ no movement observed, $3=$ joint can be moved against gravity, $5=$ normal strength against full resistance).

\section{SBT Protocol}

Up to the first attempt to discontinue ventilatory support, all subjects were ventilated similarly with a mechanical ventilator (PB840 [Puritan Bennett, Pleasanton, California] or Inter 7 Plus [CareFusion, San Diego, California]) programed in volume control mode. All subjects received an approximate tidal volume of $7 \mathrm{~mL} / \mathrm{kg}$ of predicted weight with flow sensitivity. All subjects were continuously tracked with multiparametric monitors.

After randomization, the PAV + group was ventilated exclusively with a PB840 ventilator set to spontaneous $\mathrm{PAV}+$ mode, with an adjusted percentage support to maintain subjects in a comfortable range $(0.3-0.7 \mathrm{~J} / \mathrm{L}$, which is considered an optimum working level). Success was defined as subjects remaining in the comfort zone with $\leq 40 \%$ support. The PSV group was ventilated with a PB840 or Inter 7 Plus ventilator in spontaneous mode, and the pressure support was reduced to $7 \mathrm{~cm} \mathrm{H}_{2} \mathrm{O}$. The T-tube group was disconnected from mechanical ventilation and connected to one T-piece with supplemental oxygen, adjusted to maintain $\mathrm{S}_{\mathrm{pO}_{2}}$ at $>92 \%$.

In all groups, the SBT was conducted for 30-90 min. The trial was interrupted if the following signs of intolerance were observed, each one lasting for at least $2 \mathrm{~min}$ or until resolution: breathing frequency $>35$ breaths/min, $\mathrm{S}_{\mathrm{pO}_{2}}<90 \%$, heart rate $>140$ beats/min or sustained increase/decrease in heart rate $>20 \%$, systolic blood pressure $>180$ or $<90 \mathrm{~mm} \mathrm{Hg}$, agitation, sweating, anxiety, or decreased level of consciousness. If intolerance was observed, the subject was maintained on mechanical ventilation and reassessed after $24 \mathrm{~h}$. The SBT could be repeated using the same method in the following $2 \mathrm{~d}$.

Subjects who passed the trial were extubated and given supplemental oxygen therapy via a face mask. When indicated (subjects with COPD), noninvasive ventilation was initiated immediately after extubation. Extubation failure was defined as re-intubation within $48 \mathrm{~h}$.

\section{Statistical Analysis}

After tabulation in Excel spreadsheets (Microsoft, Redmond, Washington), the variables were analyzed using STATISTICA 7 (StatSoft, Tulsa, Oklahoma). The data distribution of the quantitative variables was assessed using the Shapiro-Wilk test, and the homogeneity of the variances among groups was assessed using the Levene test. One-way analysis of variance was used for the variables (APACHE II, SOFA, RSBI, breathing frequency, $\mathrm{P}_{\mathrm{aCO}_{2}}$, and $\mathrm{P}_{\mathrm{aO}_{2}} / \mathrm{F}_{\mathrm{IO}_{2}}$ ) that were in accordance with these statistical assumptions. Variables not in accordance with assumptions (mechanical ventilation time pre-extubation [d or h], hours without sedation up to extubation, full-time sedation, ICU/hospital stay [d], maximum inspiratory pressure, Glasgow coma scale score pre- and post-extubation, MRC biceps flexion and knee flexion, duration of first SBT [min], and total number of SBTs) were analyzed using the Kruskal-Wallis non-parametric test.

The frequencies of qualitative variables were compared between groups using the chi-square test for $\mathrm{k}$ proportions: trauma without brain injury, traumatic brain injury, clinical/neurologic, clinical/non-neurologic, postoperative elective surgery, postoperative emergency surgery, COPD, congestive heart failure, obesity [body mass index $>35 \mathrm{~kg} / \mathrm{m}^{2}$ ], ICU/hospital mortality, extubation failure, needed tracheostomy, CAM-ICU total delirium score, and success in the first SBT. The frequencies of the need for noninvasive ventilation at $0,<6,6-12$, and $>12 \mathrm{~h}$ were evaluated using the McNemar test. The significance level was defined as $<.05$ for all statistical tests.

Finally, logistic regression analysis was used to check for successful extubation characteristics of each method (T-tube, PSV, and PAV+). For application of this analysis, the logit model stepwise forward method with binary response (extubation success and failure) was used. Several steps were required for this analysis: (1) selection of variables using the criterion of $P<.20$ odds ratio, which is statistically equivalent to 1.00 ; (2) obtainment of a model with a reduced number of variables, selected by using the criterion of $P<.10$ adjusted odds ratio, statistically equivalent to 1.00; and (3) obtainment of a final model after testing all possible multiple interactions using a maximization of likelihood function with the Newton-Raphson algorithm. Once the final logistic regression model was selected, the odds ratios were calculated from the formula: probability $=1 /[1+\mathrm{e}(\alpha+\Sigma(\beta \mathrm{ixi})]$, where $\alpha$ is the model constant.

\section{Results}

We admitted 486 ICU patients during the study period, but 321 were not eligible for the protocol, and 5 were excluded (Fig. 2). The sample consisted of $66.5 \%$ men and $33.5 \%$ women, with a mean age of $44.6 \mathrm{y}$. The mean time on mechanical ventilation for these subjects was $148 \mathrm{~h}$. The main cause of admission of the general study population was polytrauma associated with traumatic brain injury (27.5\%), followed by clinical morbidity without neurologic cause $(19.4 \%)$. The most frequently reported 


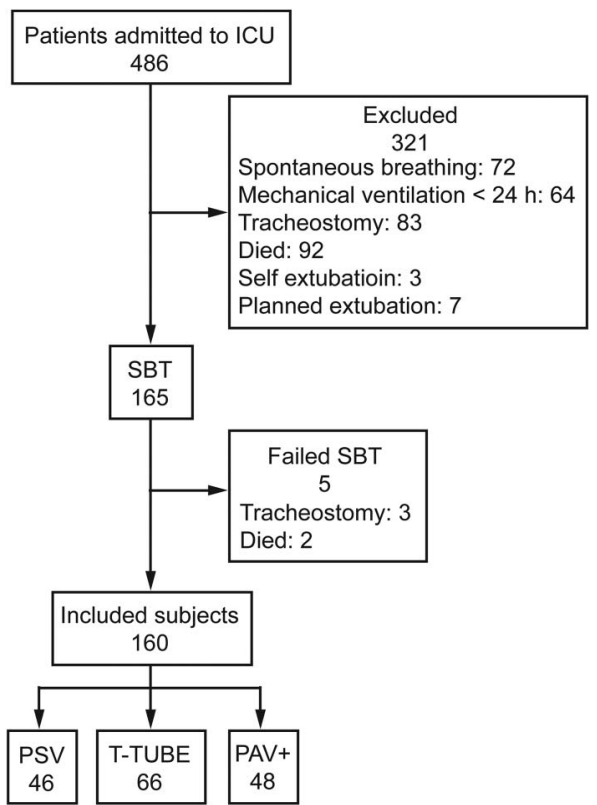

Fig. 2. General study design. In 1 y, we admitted 486 patients. Of these, 321 were not eligible for the protocol, and 5 were excluded. After inclusion, the subjects were randomly assigned to groups: T-tube (66, 41.3\%), pressure support ventilation (PSV; 46, 28.7\%), and proportional assist ventilation plus (PAV+; 48, 30\%). SBT $=$ spontaneous breathing trial.

comorbidities among the subjects were obesity (19.3\%), COPD $(22.5 \%)$, and congestive heart failure (16.9\%) (Table 1).

Sample characterization revealed that the 3 groups were similar regarding general subject characteristics, such as age, sex, severity index (APACHE II and SOFA), mechanical ventilation duration, sedation duration, reason for admission, and comorbidities. In addition, the groups were statistically similar regarding data collected on the extubation day, such as maximum inspiratory pressure, RSBI, presence of delirium, and muscle strength (see Table 1). Delirium could be evaluated with the CAM-ICU questionnaire in only 110 subjects.

Regarding hospitalization, no significant difference was observed in ICU stay and mortality among the groups. The re-intubation frequency was higher for the PSV group, followed by the T-tube group and the PAV + group; however, these differences were not statistically significant $(P>.05)$ (Table 2).

The first SBT attempt was successful for 121 (76\%) subjects, with no statistical differences between the proportions in the groups $(P>.05)$. The T-tube group spent less time taking the trial compared with the PSV and PAV+ groups $(P<.001)$. No statistical significance was observed regarding the number of SBTs performed in each group (Table 3).

Re-intubation was required for 23 subjects within $48 \mathrm{~h}$; of these, $11(48 \%)$ required tracheostomy, $9(39 \%)$ were re-extubated successfully, and $3(13 \%)$ died. The reasons for re-intubation were respiratory failure in 8 subjects (34.8\%), decreased level of consciousness in 5 (21.8\%), upper-airway obstruction (laryngeal edema) in 4 (17.4\%), excess lung secretion/inability to protect airways in $3(13 \%)$, and bronchospasm in 3 (13\%). The outcomes of each group are shown in Figure 3.

\section{Prognostic Factors Related to Incidence of Extubation}

After univariate analysis, all variables were combined for the performance of logistic regression for each group. This analysis revealed that all groups had a model with an adequate fit. The models are shown in Table 4.

In the T-tube group, subjects with successful extubation had a lower average RSBI $(P=.048)$, higher-mean $\mathrm{P}_{\mathrm{aO}_{2}} / \mathrm{F}_{\mathrm{IO}_{2}}(P=.01)$, and lower-mean stay in the $\mathrm{ICU}$ $(P=.02)$. In the PSV group, subjects who were successfully extubated remained in the ICU for a shorter period $(P=.002)$. Finally, in the PAV + group, subjects with successful or failed extubation had equal probability on $\mathrm{P}_{\mathrm{aO}_{2}} / \mathrm{F}_{\mathrm{IO}_{2}}(P=.05)$, but those who failed stayed for more days in the ICU $(P=.02)$.

\section{Discussion}

The method chosen for weaning will influence extubation success or failure and morbidity/mortality of extubated patients. ${ }^{20}$ Delay in weaning from mechanical ventilation is associated with several complications, such as ventilator-associated pneumonia, hemodynamic disturbances, muscle wasting and weakness, and tracheal injury. ${ }^{1}$ Thus, studies aimed at weaning critically ill patients are important.

The subjects in this study were similar with respect to baseline characteristics, severity index, and duration of mechanical ventilation and sedation. However, when divided into groups, traumatic brain injury was the leading cause of admission in the PSV and T-tube groups, whereas the main cause was trauma without brain injury, followed by medical/non-neurologic causes in the PAV + group (see Table 1). No significant difference was observed among the groups. According to Namen et $a \mathrm{al},{ }^{21}$ when a specific population such as subjects with traumatic brain injury is considered, many subjects may pass weaning trials but fail extubation and progress to respiratory failure due to neurologic changes (airway obstruction, dysphagia, and decreased tone). However, we found no statistically significant relationship between extubation failure and reason for admission in our study. Subjects involved in previous weaning studies exhibited variable disease severities, with a mean APACHE II score of $<20 .{ }^{22}$ The average was 22.7 in our study, indicating greater subject severity. 
Table 1. Subject Characteristics

\begin{tabular}{|c|c|c|c|c|c|}
\hline Characteristic & Total $(n=160)$ & T-Tube $(n=66)$ & $\operatorname{PSV}(n=46)$ & $\mathrm{PAV}+(n=48)$ & $P$ \\
\hline Age, mean \pm SD y & $44.5 \pm 20.7$ & $46.8 \pm 20.8$ & $44.3 \pm 19.8$ & $41.4 \pm 20.2$ & .52 \\
\hline Males, $n(\%)$ & $105(65.6)$ & $47(66.5)$ & $27(58.7)$ & $31(64.6)$ & .38 \\
\hline APACHE II score on admission, mean $\pm \mathrm{SD}$ & $22.7 \pm 4.8$ & $22.7 \pm 4.2$ & $21.9 \pm 5.4$ & $23.3 \pm 5.1$ & .38 \\
\hline SOFA score on admission, mean $\pm \mathrm{SD}$ & $9.3 \pm 2.4$ & $9.1 \pm 2.2$ & $9.4 \pm 2.7$ & $9.1 \pm 2.6$ & .67 \\
\hline \multicolumn{6}{|l|}{ Invasive mechanical ventilation pre-extubation } \\
\hline Mean \pm SD d & $6.6 \pm 4.2$ & $7.1 \pm 4.1$ & $6.6 \pm 4.4$ & $6.1 \pm 4.2$ & .42 \\
\hline Mean $\pm \mathrm{SD} h$ & $148 \pm 102.9$ & $161.4 \pm 99$ & $143.3 \pm 103.5$ & $133.6 \pm 107.4$ & .27 \\
\hline Without sedation up to extubation, mean $\pm \mathrm{SD} h$ & $49.2 \pm 47.1$ & $51.4 \pm 50.2$ & $49.7 \pm 46.8$ & $45.8 \pm 43.4$ & .47 \\
\hline Total sedation time, mean $\pm \mathrm{SD}$ h & $88.3 \pm 77.3$ & $98.5 \pm 79.3$ & $80.3 \pm 70.8$ & $81.7 \pm 80.2$ & .36 \\
\hline \multicolumn{6}{|l|}{ Admission reason, $n(\%)$} \\
\hline Traumatic brain injury & $44(27.5)$ & $22(33.3)$ & $13(28.2)$ & $9(18.7)$ & .23 \\
\hline Trauma without brain injury & $28(17.5)$ & $10(15.1)$ & $6(13.3)$ & $12(25)$ & .25 \\
\hline Medical/neurologic & $20(12.5)$ & $8(12.1)$ & $8(17.3)$ & $4(8.3)$ & .41 \\
\hline Medical/non-neurologic & $31(19.4)$ & $11(16.7)$ & $7(15.2)$ & $13(27)$ & .27 \\
\hline Postoperative elective surgery & $15(9.4)$ & $7(10.7)$ & $3(6.5)$ & $5(10.5)$ & .73 \\
\hline Postoperative urgent surgery & $22(13.7)$ & $8(12.1)$ & $9(19.5)$ & $5(10.5)$ & .85 \\
\hline \multicolumn{6}{|l|}{ Comorbidities, $n(\%)$} \\
\hline COPD & $36(22.5)$ & $18(27.2)$ & $11(23.9)$ & $7(14.6)$ & .27 \\
\hline Congestive heart failure & $27(16.9)$ & $13(19.6)$ & $9(19.5)$ & $5(10.4)$ & .36 \\
\hline Obesity $\left(\mathrm{BMI} \geq 30 \mathrm{~kg} / \mathrm{m}^{2}\right)$ & $31(19.3)$ & $13(19.6)$ & $10(21.7)$ & $8(16.6)$ & .82 \\
\hline \multicolumn{6}{|l|}{ Extubation day data } \\
\hline $\mathrm{P}_{\mathrm{I}_{\max }}$, mean $\pm \mathrm{SD} \mathrm{cm} \mathrm{H}_{2} \mathrm{O}$ & $-28 \pm 15.5$ & $-27.5 \pm 15.6$ & $-26.6 \pm 13.1$ & $-29.8 \pm 17.5$ & .19 \\
\hline $\mathrm{RSBI}$, mean $\pm \mathrm{SD}$ & $54.8 \pm 27.2$ & $43 \pm 29.0$ & $54.8 \pm 28.3$ & $53.7 \pm 23.4$ & .99 \\
\hline Breathing frequency, mean \pm SD breaths/min & $22.1 \pm 6$ & $22.8 \pm 5.6$ & $21.8 \pm 6$ & $21.6 \pm 6.4$ & .55 \\
\hline $\mathrm{P}_{\mathrm{aCO}_{2}}$, mean $\pm \mathrm{SD} \mathrm{mm} \mathrm{Hg}$ & $41.1 \pm 6.7$ & $42.3 \pm 7.5$ & $40 \pm 6.1$ & $40.3 \pm 5.8$ & .14 \\
\hline $\mathrm{P}_{\mathrm{aO}_{2}} / \mathrm{F}_{\mathrm{IO}_{2}}$, mean $\pm \mathrm{SD} \mathrm{mm} \mathrm{Hg}$ & $287.2 \pm 78.5$ & $288.1 \pm 72.3$ & $290.2 \pm 75.3$ & $283.2 \pm 90.3$ & .91 \\
\hline \multicolumn{6}{|l|}{ Glasgow coma scale score, mean $\pm \mathrm{SD}$} \\
\hline Pre-extubation & $10.3 \pm 0.7$ & $10.4 \pm 0.6$ & $10.4 \pm 0.8$ & $10.3 \pm 0.7$ & $>.99$ \\
\hline Post-extubation & $12.6 \pm 1.9$ & $12.8 \pm 1.7$ & $12.7 \pm 2.1$ & $12.4 \pm 1.8$ & .34 \\
\hline \multicolumn{6}{|l|}{$\mathrm{MRC}$, mean $\pm \mathrm{SD}$} \\
\hline Biceps flexion & $3.06 \pm 1.08$ & $3.01 \pm 1.04$ & $3.03 \pm 1.03$ & $3.14 \pm 1.17$ & .50 \\
\hline Knee flexion & $2.92 \pm 1.1$ & $2.94 \pm 1.10$ & $2.78 \pm 0.90$ & $3 \pm 1.20$ & .50 \\
\hline Needed NIV post-extubation, $\%$ & 22.5 & 24.2 & 23.9 & 18.8 & .77 \\
\hline Delirium, $\%$ & 55.4 & 61.9 & 53.1 & 50 & .55 \\
\hline $\begin{array}{l}\text { PSV }=\text { pressure support ventilation } \\
\text { PAV + = proportional assist ventilation plus } \\
\text { APACHE II = Acute Physiology and Chronic Health Evaluation II } \\
\text { SOFA = Sequential Organ Failure Assessment } \\
\text { BMI = body mass index } \\
\text { P }_{\mathrm{I}_{\max }=\text { maximum inspiratory pressure }} \\
\text { RSBI = rapid shallow breathing index } \\
\text { MRC = Medical Research Council } \\
\text { NIV = noninvasive mechanical ventilation }\end{array}$ & & & & & \\
\hline
\end{tabular}

In this study, we compared 3 methods used as SBTs in an adult ICU, and we found no significant differences among groups regarding extubation failure, mortality, and ICU/hospital stay. Although we found no reports in the scientific literature on the use of PAV + as an SBT, many researchers have used it as a weaning method. A randomized study of 208 subjects on PAV+ or PSV for $48 \mathrm{~h}$ analyzed the need to return to a controlled mode. ${ }^{22}$ The authors reported that significantly fewer adjustments and returns to controlled ventilation were required with $\mathrm{PAV}+$, which also had lower ventilator asynchrony and a greater ability to maintain a more constant tidal volume. Furthermore, as in our study, the authors found no significant difference regarding mechanical ventilation days and extubation failure rate. ${ }^{22}$

In prospective observational studies comparing $\mathrm{PAV}+$ and PSV during the weaning process regarding tolerance, duration of invasive mechanical ventilation, and clinical outcomes, no significant differences were found among the groups in mechanical ventilation duration, re-intubation rate, mortality, need for tracheostomy, and percentage of post-extubation noninvasive ventilation, 
Table 2. Outcomes

\begin{tabular}{|c|c|c|c|c|c|}
\hline Outcome & Total $(N=160)$ & T-Tube $(n=66)$ & $\operatorname{PSV}(n=46)$ & $\mathrm{PAV}+(n=48)$ & $P$ \\
\hline $\mathrm{ICU}$ stay, mean $\pm \mathrm{SD} d$ & $11.8 \pm 8.1$ & $12 \pm 8.1$ & $11.9 \pm 7.4$ & $11.5 \pm 8.9$ & .97 \\
\hline Hospital stay, mean $\pm \mathrm{SD} d$ & $25 \pm 17.2$ & $25.1 \pm 16.5$ & $27.6 \pm 19.8$ & $22.2 \pm 15.4$ & .26 \\
\hline Time to re-intubation, mean \pm SD h & $13.3 \pm 12.1$ & $13.1 \pm 11.7$ & $10.5 \pm 8.6$ & $17.6 \pm 16.9$ & .57 \\
\hline ICU mortality, $n(\%)$ & $6(3.7)$ & $5(7.6)$ & $1(2.2)$ & 0 & .09 \\
\hline Hospital mortality, $n(\%)$ & $16(10)$ & $5(7.6)$ & $6(13)$ & $5(10.4)$ & .63 \\
\hline Extubation failure, $n(\%)$ & $24(15)$ & $10(15)$ & $8(17)$ & $6(12.5)$ & .80 \\
\hline Required tracheostomy, $n(\%)$ & $12(7.5)$ & $2(3)$ & $6(13)$ & $4(8.3)$ & .59 \\
\hline
\end{tabular}

PSV $=$ pressure support ventilation

$\mathrm{PAV}+=$ proportional assist ventilation plus

Table 3. Data From SBTs

\begin{tabular}{|c|c|c|c|c|}
\hline Data & T-Tube $(n=66)$ & $\operatorname{PSV}(n=46)$ & $\mathrm{PAV}+(n=48)$ & $P$ \\
\hline Successful first SBT, $n(\%)$ & $51(77.2)$ & $32(69.5)$ & $38(79.1)$ & .51 \\
\hline Time spent in first SBT, mean \pm SD min & $35.3 \pm 7.5^{*}$ & $45.7 \pm 12$ & $45.8 \pm 15.8$ & $<.001$ \\
\hline One SBT, $n(\%)$ & $50(75.8)$ & $32(69.4)$ & $38(79.2)$ & .55 \\
\hline Two SBTs, $n(\%)$ & $10(15.2)$ & $7(15.3)$ & $8(16.6)$ & .97 \\
\hline Three SBTs, $n(\%)$ & $6(9)$ & $7(15.3)$ & $2(4.2)$ & .18 \\
\hline $\begin{array}{l}* \text { The T-tube groups was different from the other } 2 \text { grour } \\
\text { SBT }=\text { spontaneous breathing trial } \\
\text { PSV = pressure support ventilation } \\
\text { PAV }+ \text { = proportional assist ventilation plus }\end{array}$ & & & & \\
\hline
\end{tabular}

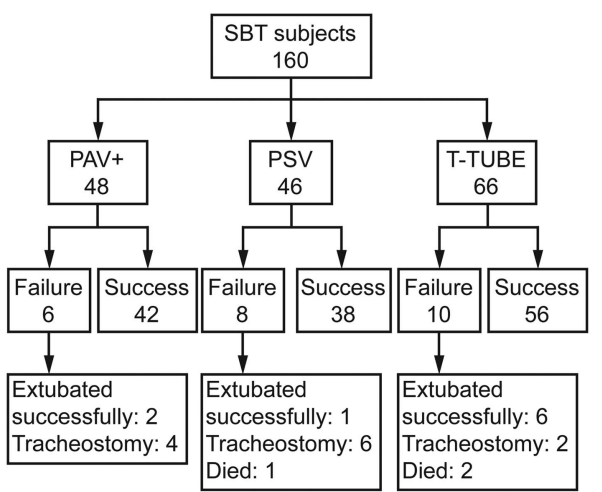

Fig. 3. Post-extubation outcome by groups. There was no significant difference in extubation failure rates between the groups $(P=.80)$. SBT $=$ spontaneous breathing trial; $\mathrm{PAV}+=$ proportional assist ventilation plus; $P S V=$ pressure support ventilation.

indicating that PSV and PAV + could be considered clinically equivalent in relation to weaning. ${ }^{23,24} \mathrm{~A}$ pilot study demonstrated the safety and feasibility of the $\mathrm{PAV}+$ algorithm for weaning, ${ }^{25}$ confirming the findings of our study.

The time that T-tube group remained in the trial was significantly shortened by $10 \mathrm{~min}$, which demonstrates the staff's confidence in the T-tube; however, the testing time did not affect the incidence of extubation fail- ure or clinical outcomes. These data confirm the results of a study in which the time of spontaneous breathing before extubation was compared at 30 and $120 \mathrm{~min}$; the same success and failure rates and ICU and hospital mortalities were found at the different spontaneous ventilation times. ${ }^{1}$

Analyzing subjects who failed extubation in isolation revealed that they spent more days in the ICU and had worse RSBI and pre-extubation $\mathrm{P}_{\mathrm{aO}_{2}} / \mathrm{F}_{\mathrm{IO}_{2}}$ results. These findings corroborate previous studies showing that RSBI is one of the most widely used predictors of weaning, where high values $(>105 \mathrm{cycles} / \mathrm{min} \cdot \mathrm{L})$ are associated with failed extubation. ${ }^{26-28}$ In addition, another analyzed parameter is $\mathrm{P}_{\mathrm{aO}_{2}} / \mathrm{F}_{\mathrm{IO}_{2}}$, where values $<200 \mathrm{~mm} \mathrm{Hg}$ are related to failed extubation. ${ }^{19}$ A previous study found that extubation failure was a significant independent predictor of increased ICU stay. ${ }^{29}$

ICU-acquired weakness during mechanical ventilation causes deterioration of global muscle strength, tetraparesis, and reduced respiratory muscle strength, leading to longer mechanical ventilation and failed weaning and extubation. ${ }^{30}$ The subjects in this study showed an overall reduction in muscle strength, evidenced in the upper (grade 3) and lower (grade 2) limbs.

The success rates of the PAV +, T-tube group, and PSV group were 85,83 , and $90 \%$, respectively. Therefore, the 
Table 4. Logistic Regression Analysis of Prognostic Factors Related to Incidence of Extubation

\begin{tabular}{|c|c|c|c|c|c|c|c|}
\hline \multirow{2}{*}{ Source } & \multirow{2}{*}{ Value } & \multirow{2}{*}{ SE } & \multirow{2}{*}{ Wald Chi-Square Test } & \multirow{2}{*}{ Probability $>$ chi-square } & \multirow{2}{*}{ Odds Ratio } & \multicolumn{2}{|c|}{ Odds Ratio } \\
\hline & & & & & & $-95 \%$ & $+95 \%$ \\
\hline \multicolumn{8}{|l|}{ T-tube } \\
\hline RSBI & -0.04 & 0.02 & 3.90 & 0.05 & 1.04 & 1.00 & 1.07 \\
\hline $\mathrm{P}_{\mathrm{aO}_{2}} / \mathrm{F}_{\mathrm{IO}_{2}}$ & 0.02 & 0.01 & 6.56 & 0.01 & 1.02 & 1.01 & 1.04 \\
\hline ICU stay & -0.12 & 0.06 & 5.08 & 0.02 & 1.13 & 1.02 & 1.26 \\
\hline \multicolumn{8}{|l|}{ PSV } \\
\hline ICU stay & -0.17 & 0.06 & 9.47 & 0.002 & 1.19 & 1.07 & 1.33 \\
\hline \multicolumn{8}{|l|}{$\mathrm{PAV}+$} \\
\hline $\mathrm{P}_{\mathrm{aO}_{2}} / \mathrm{F}_{\mathrm{IO}_{2}}$ & -0.02 & 0.01 & 3.84 & 0.05 & 0.98 & 0.96 & 1.00 \\
\hline ICU stay & -0.34 & 0.14 & 5.81 & 0.02 & 1.40 & 1.07 & 1.84 \\
\hline \multicolumn{8}{|c|}{$\begin{array}{l}\text { PSV }=\text { pressure support ventilation } \\
\text { PAV }+=\text { proportional assist ventilation }\end{array}$} \\
\hline
\end{tabular}

re-intubation rates were 15,17 , and $10 \%$ for the T-tube, PSV, and PAV groups, respectively, which are consistent with the rates reported by other authors (11-23.5\%). . $^{31-33}$

Extubation failure may occur because of upper-airway obstruction, ineffective cough, and excessive respiratory secretions that cannot be managed by the patient. ${ }^{33} \mathrm{An}$ other potential reason for extubation failure is loss of positive pressure in the chest after extubation in subjects weaned to PSV. ${ }^{27}$ The reasons for failure and re-intubation in our study were respiratory failure, followed by decreased level of consciousness and airway obstruction.

This study had several limitations. The $\mathrm{F}_{\mathrm{IO}_{2}}$ during each method was not necessary identical because in the T-tube group, the $\mathrm{F}_{\mathrm{IO}_{2}}$ was not measured. However, according to the protocol, all subjects had to maintain an $\mathrm{S}_{\mathrm{pO}_{2}}$ of $\geq 91 \%$, indicating that no subject developed hypoxemia during the SBT. The main limitation is that the reliability of the results may have been compromised because this was a single-center study with a small sample. However, the number of subjects in each group was sufficient for adequate statistical calculations. Furthermore, the study was carried out by a single group, resulting in less heterogeneity in subject management and monitoring. The number of subjects was insufficient to evaluate the most powerful outcomes (such as mortality); however, the objective of this study was to assess the reliability of the PAV+ method as an SBT, which was clearly demonstrated.

\section{Conclusions}

In summary, our results indicate that the PAV + method is a valid alternative for use as an SBT. When compared with the currently used methods (T-tube and PSV), no significant differences were found in the rate of extubation failure, duration of mechanical ventilation, or ICU and hospital stays. In addition, this method exhibited high pre- dictive power related to extubation, confirming its applicability, efficacy, and safety compared with the T-tube and PSV.

\section{REFERENCES}

1. Thille AW, Cortés-Puch I, Esteban A. Weaning from the ventilator and extubation in ICU. Curr Opin Crit Care 2013;19(1):57-64.

2. Macnaughton PD. Ventilatory support in the ICU. Anaesth Intensive Care Med 2007;8(11):489-494.

3. Dries DJ, McGonigal MD, Malian MS, Bor BJ, Sullivan C. Protocoldriven ventilator weaning reduces use of mechanical ventilation, rate of early reintubation, and ventilator-associated pneumonia. J Trauma 2004;56(5):943-951; discussion 951-952.

4. Hannan LM, Tan S, Hopkinson K, Marchingo E, Rautela L, Detering $\mathrm{K}$, et al. Inpatient and long-term outcomes of individuals admitted for weaning from mechanical ventilation at a specialized ventilation weaning unit. Respirology 2013;18(1):154-160.

5. Lone NI, Walsh TS. Prolonged mechanical ventilation in critically ill patients: epidemiology, outcomes and modelling the potential cost consequences of establishing a regional weaning unit. Crit Care 2011; 15(2):R102

6. Ambrosino N, Venturelli E, Vagheggini G, Clini E. Rehabilitation, weaning and physical therapy strategies in chronic critically ill patients. Eur Respir J 2012;39(2):487-492.

7. Artime CA, Hagberg CA. Tracheal extubation. Respir Care 2014; 59(6):991-1002; discussion 1002-1005.

8. Esteban A, Anzueto A, Alía I, Gordo F, Apezteguía C, Pálizas F, et al. How is mechanical ventilation employed in the intensive care unit? An international utilization review. Am J Respir Crit Care Med 2000;161(5): 1450-1458

9. Krishnan JA, Moore D, Robeson C, Rand CS, Fessler HE. A prospective, controlled trial of a protocol-based strategy to discontinue mechanical ventilation. Am J Respir Crit Care Med 2004;169(6): 673-678.

10. Vitacca M. Therapist driven protocols. Monaldi Arch Chest Dis 2003;59(4):342-344

11. Blackwood B, Alderdice F, Burns KE, Cardwell CR, Lavery GG, O'Halloran P. Protocolized versus non-protocolized weaning for reducing the duration of mechanical ventilation in critically ill adult patients. Cochrane Database Syst Rev 2014;(5):CD006904. 


\section{PAV,+ T-Tube Ventilation, AND PSV for SBTs}

12. MacIntyre NR, Cook DJ, Ely EW Jr, Epstein SK, Fink JB, Heffner $\mathrm{JE}$, et al. Evidence-based guidelines for weaning and discontinuing ventilatory support. Chest 2001;120(6 Suppl):375S-395S.

13. Tobin MJ. Of principles and protocols and weaning (editorial). Am J Respir Crit Care Med 2004;169(6):661-662.

14. Kacmarek RM. Proportional assist ventilation and neurally adjusted ventilatory assist. Respir Care 2011;56(2):140-148; discussion 149-152.

15. Cordioli RL, Akoumianaki E, Brochard L. Nonconventional ventilation techniques. Curr Opin Crit Care 2013;19(1):31-37.

16. Bosma K, Ferreyra G, Ambrogio C. Patient-ventilator interaction and sleep in mechanically ventilated patients: pressure support versus proportional assist ventilation. Crit Care Med 2007;35(4): 1048-1054

17. Caruso P, Friedrich C, Denari SD, Ruiz SA, Deheinzelin D. The unidirectional valve is the best method to determine maximal inspiratory pressure during weaning. Chest 1999;115(4):1096-1101.

18. Yang KL, Tobin MJ. A prospective study of indexes predicting the outcome of trials of weaning from mechanical ventilation. $\mathrm{N}$ Engl J Med 1991;324(21):1445-1450.

19. Khamiees M, Raju P, DeGirolamo A, Amoateng-Adjepong Y, Manthous CA. Predictors of extubation outcome in patients who have successfully completed a spontaneous breathing trial. Chest 2001; 120(4):1262-1270.

20. Ely EW. Weaning from mechanical ventilation: acute and chronic management. Chest 2000;15:522-529.

21. Namen AM, Ely EW, Tatter SB, Case LD, Lucia MA, Smith A, et al. Predictors of successful extubation in neurosurgical patients. Am J Respir Crit Care Med 2001;163(3):658-664.

22. Xirouchaki N, Kondili E, Vaporidi K, Xirouchakis G, Klimathianaki M, Gavriilidis G, et al. Proportional assist ventilation with loadadjustable gain factors in critically ill patients: comparison with pressure support. Intensive Care Med 2008;34(11):2026-2034.

23. Aguirre-Bermeo H, Bottiroli M, Italiano S, Roche-Campo F, Santos JA, Alonso M, Mancebo J. [Pressure support ventilation and pro- portional assist ventilation during weaning from mechanical ventilation]. Med Intensiva 2014;38(6):363-370. Article in Spanish.

24. Costa R, Spinazzola G, Cipriani F, Ferrone G, Festa O, Arcangeli A, et al. A physiologic comparison of proportional assist ventilation with load-adjustable gain factors $(\mathrm{PAV}+)$ versus pressure support ventilation (PSV). Intensive Care Med 2011;37(9):1494-1500.

25. Bosma K, Read B, Nikoo M, Bentall T, Harris C, Jones P, et al. A randomized trial comparing weaning from mechanical ventilation on pressure support vs. proportional assist ventilation: a pilot study (abstract). Chest 2013;144:892A.

26. Nemer SN, Barbas CS. Predictive parameters for weaning from mechanical ventilation. J Bras Pneumol 2011;37(5):669-679.

27. Eskandar N, Apostolakos MJ. Weaning from mechanical ventilation. Crit Care Clin 2007;23(2):263-274.

28. Boles JM, Bion J, Connors A, Herridge M, Marsh B, Melot C, et al. Weaning from mechanical ventilation. Eur Respir J 2007;29(5):10331056.

29. Epstein SK, Ciubotaru RL, Wong JB. Effect of failed extubation on the outcome of mechanical ventilation. Chest 1997;112(1):186-192.

30. Gil BA, Frutos-Vivar F, Esteban A. Deleterious effects of reintubation of mechanically ventilated patients. Clin Pulm Med 2003;10(4): 226-230.

31. Esteban A, Alía I, Gordo F, Fernández R, Solsona JF, Vallverdú I, et al. The Spanish Lung Failure Collaborative Group. Extubation outcome after spontaneous breathing trials with T-tube or pressure support ventilation. Am J Respir Crit Care Med 1997;156(2 Pt 1):459-465.

32. Lellouche F, Mancebo J, Jolliet P, Roeseler J, Schortgen F, Dojat M, et al. A multicenter randomized trial of computer-driven protocolized weaning from mechanical ventilation. Am J Respir Crit Care Med 2006;174(8):894-900.

33. Deab SA, Bellani, G. Extubation failure after successful spontaneous breathing trial: prediction is still a challenge (editorial)! Respir Care 2014;59(2):301-302.

This article is approved for Continuing Respiratory Care Education credit. For information and to obtain your CRCE

(free to AARC members) visit

www.rcjournal.com

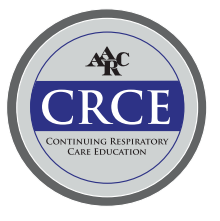

